Portland State University

PDXScholar

\title{
VA Healthcare Costs of a Collaborative Intervention for Chronic Pain in Primary Care
}

\author{
Kathryn C. Dickinson \\ Veterans Affairs Portland Health Care System \\ Rajiv Sharma \\ Portland State University, sharmar@pdx.edu \\ Jonathan P. Duckart \\ Veterans Affairs Portland Health Care System \\ Kathryn Corson \\ Oregon Health \& Science University \\ Martha S. Gerrity \\ Veterans Affairs Portland Health Care System
}

See next page for additional authors

Follow this and additional works at: https://pdxscholar.library.pdx.edu/econ_fac

Part of the Economics Commons, and the Medicine and Health Commons

Let us know how access to this document benefits you.

\section{Citation Details}

Dickinson KC, Sharma R, Duckart JP, Corson K, Gerrity MS, Dobscha SK. VA Healthcare costs of a collaborative intervention for chronic pain in primary care. Medical Care 48, 38-44, 2010.

This Article is brought to you for free and open access. It has been accepted for inclusion in Economics Faculty Publications and Presentations by an authorized administrator of PDXScholar. Please contact us if we can make this document more accessible: pdxscholar@pdx.edu. 
Authors

Kathryn C. Dickinson, Rajiv Sharma, Jonathan P. Duckart, Kathryn Corson, Martha S. Gerrity, and Steven K. Dobscha 


\title{
VA Healthcare Costs of a Collaborative Intervention for Chronic Pain in Primary Care
}

\author{
Kathryn C. Dickinson, MPH, * Rajiv Sharma, PhD, ${ }^{* \dagger}$ Jonathan P. Duckart, MPS, * \\ Kathryn Corson, PhD, * $\neq$ Martha S. Gerrity, MD, ${ }^{*} \$ \rrbracket$ and Steven K. Dobscha, MD* $\neq$
}

Background: Chronic pain is costly to individuals and the healthcare system, and is often undertreated. Collaborative care models show promise for improving treatment of patients with chronic pain. The objectives of this article are to report the incremental benefit and incremental health services costs of a collaborative intervention for chronic pain from a veterans affairs (VA) healthcare perspective.

Methods: Data on VA treatment costs incurred by participants were obtained from the VA's Decision Support System for all utilization except certain intervention activities which were tracked in a separate database. Outcome data were from a cluster-randomized trial of a collaborative intervention for chronic pain among 401 primary care patients at a VA medical center. Intervention group participants received assessments and care management; stepped-care components were offered to patients requiring more specialized care. The main outcome measure was pain disability-free days (PDFDs), calculated from Roland-Morris Disability Questionnaire scores.

Results: Participants in the intervention group experienced an average of 16 additional PDFDs over the 12-month follow-up window as compared with usual care participants; this came at an adjusted incremental cost of \$364 per PDFD for a typical participant. Important predictors of costs were baseline medical comorbidities, depression severity, and prior year's treatment costs.

Conclusions: This collaborative intervention resulted in more pain disability-free days and was more expensive than usual care. Further research is necessary to identify if the intervention is more costeffective for some patient subgroups and to learn whether pain improvements and higher costs persist after the intervention has ended.

Key Words: chronic pain, collaborative care, pain improvement, cost, primary care

(Med Care 2010;48: 38-44)

From the *Portland Center for the Study of Chronic, Comorbid Mental and Physical Disorders, Portland VA Medical Center, Portland, OR; †Department of Economics, Portland State University, Portland, OR; Departments of $\ddagger$ Psychiatry, and §Medicine, Oregon Health and Science University, Portland, OR; and $\mid$ Division of Hospital and Specialty Medicine, Portland VA Medical Center, Portland OR.

Supported by the Department of Veterans Affairs, Veterans Health Administration, Health Services Research and Development Service Projects PMI 03-195 and REA 06-174.

Reprints: Kathryn C. Dickinson, MPH, Portland VA Medical Center, P.O. Box 1034 (P3DEP-PC), Portland, OR 97207. E-mail: kathryn.dickinson@ va.gov.

Copyright (C) 2009 by Lippincott Williams \& Wilkins

ISSN: 0025-7079/10/4801-0038
Chronic, noncancer pain is associated with considerable - physical and psychosocial impairment, and increased healthcare utilization and costs. ${ }^{1-4}$ Chronic pain results not only in direct costs for treatment but also in increased disability compensation, decreased productivity, and lost tax revenue. ${ }^{3}$ It is estimated that common pain conditions cost the United States $\$ 61.2$ billion per year in lost productive time alone. ${ }^{5}$ There are many approaches to treating chronic pain, including medications, surgery, physical therapy, anesthesiology interventions, multidisciplinary pain centers, behavioral interventions, and alternative therapies such as chiropractic manipulation and acupuncture; many are expensive and rarely offer a complete cure. ${ }^{3}$ Chronic pain patients are frequently managed with medications such as opioids, and medication costs can easily exceed $\$ 4000$ per year. ${ }^{3}$ Providers and patients often search for a satisfactory combination of treatments to ease suffering and increase functional status, while minimizing costs to the individual and the healthcare system.

Collaborative care interventions based in primary care have emerged as one successful approach to supporting guideline-concordant care and improving outcomes for chronic conditions. $^{6-8}$ These interventions are based on the chronic care model developed by Wagner et $\mathrm{al}^{9}$; they seek to optimize patient-clinician interactions while providing system support, typically in the form of patient activation, clinician feedback, and care management. The "Study of the Effectiveness of A Collaborative Approach to Pain" (SEACAP) sought to assess whether a novel collaborative care intervention would result in improvements in chronic pain and depression outcomes compared with treatment as usual (TAU) among patients treated in a veterans affairs (VA) primary care setting. ${ }^{10,11}$ SEACAP showed modest effects, with intervention patients showing greater improvements in self-reported pain-related disability, pain interference, pain intensity, global impression of change, and depression over 12 months compared with TAU patients. The differences in scores between baseline and 12 months for the intervention group and the TAU group, respectively, were -1.4 versus -0.2 for the Roland-Morris Disability Questionnaire (RMDQ) ${ }^{12,13}$ (pain-related disability, SEACAP's primary outcome), -4.7 versus -0.6 for the Chronic Pain Grade Pain Intensity subscale, ${ }^{14}$ and -3.7 versus -1.2 for the Patient Health Questionnaire- $9^{15}$ (depression). The objectives of this manuscript are to report the incremental benefit (described in pain disability-free days) 
and incremental health services costs of the SEACAP intervention from a VA healthcare perspective.

\section{METHODS}

\section{Design}

SEACAP was a cluster-randomized trial of a collaborative intervention entitled "Assistance with Pain Treatment" (APT). APT was designed to educate and activate patients and clinicians, and to facilitate care. APT and SEACAP design and results have been described in detail elsewhere. ${ }^{10,11}$ The VA Medical Center (VAMC) institutional review board approved the study and all patients and participating primary care clinicians gave written informed consent.

SEACAP was conducted in 3 urban and 2 rural primary care clinics of 1 VAMC. All staff primary care clinicians were eligible to participate $(\mathrm{N}=54)$. Of the 46 who agreed to participate, 2 left their VA primary care practices before patient enrollment began and 2 had no patients enroll. The remaining clinicians were randomly assigned to intervention $(n=20)$ or TAU $(n=22)$ prior to patient recruitment using stratified random assignment. Randomization was stratified by professional training (nurse practitioner or physician assistant vs. physician), the proportion of their patients currently receiving opioid prescriptions, and distance from the main VAMC site ( $>15$ vs. $\leq 15$ miles). We detected no differences between participating and nonparticipating clinicians in terms of professional training, distance from the main hospital, proportion of patients receiving prescriptions for opioids, or panel size. Patients enrolled in the trial were assigned to the same group as their primary care clinicians, yielding 187 in the intervention group and 214 in TAU.

Inclusion criteria were medical record documentation of a musculoskeletal pain diagnosis, pain of at least 12 weeks duration, Chronic Pain Grade ${ }^{14}$ intensity and interference item scores each $\geq 4$ (indicating moderate or greater severity), and regular access to a telephone. Exclusion criteria included previously documented diagnoses of fibromyalgia, chronic fatigue syndrome, or somatization disorder. We also excluded patients with bipolar disorder, psychotic disorder, dementia, terminal illness, suicidal ideation requiring urgent attention, and patients whose medical records contained special flags indicating a history of disruptive behavior.

\section{Treatment}

APT is based on Wagner's chronic care model, ${ }^{9}$ previous collaborative interventions ${ }^{7,16-20}$ and multidisciplinary pain approaches, ${ }^{21-24}$ chronic pain treatment guideline criteria having at least fair to moderate evidence supporting their impact on pain outcomes, ${ }^{25-27}$ and brief activating interventions for back pain. ${ }^{28}$ The 2 key members of the APT team were a full-time clinical psychologist care manager and a VAMC internist who spent up to 1 day per week on APT team activities. A physical therapist also participated in some group educational meetings. Clinicians in the intervention group received an initial educational program followed by ongoing contacts with the APT team for feedback and recommendations. All intervention group patients received assessments and care management, while stepped-care compo- nents such as APT internist or mental health consultation were offered to those patients requiring more intensive or specialized care approaches. During initial assessments, the care manager sought to identify fear-avoidance beliefs, such as fear of movement or of pain exacerbations, explored for treatment barriers, screened for comorbid psychiatric disorders (including depression and substance misuse), and developed individualized functional goals. The care manager and intervention internist then developed treatment recommendations that were communicated to the patient's primary care clinician. In some cases, the internist also interacted directly with patients to discuss symptoms or provide additional support. Patients were contacted by the care manager every 2 months after the initial assessment for follow-up, goal modification, encouragement, and administration of pain, depression, and alcohol measures. Additionally, intervention participants were encouraged to attend a 4-session workshop co-led by the care manager and internist or physical therapist; sessions included education, skill practice, and support for goal setting and attainment. The TAU group received routine pain care from their primary care clinicians. Both TAU and intervention clinicians had access to the specialty pain clinic, ancillary services including physical, occupational, and recreational therapies, and co-located mental health services.

\section{Outcome Measures}

For SEACAP main analyses, the primary outcome measure was the RMDQ. ${ }^{12,13}$ The RMDQ has content and construct validity, internal consistency, and responsiveness to pain among patients with chronic pain. ${ }^{13,29}$ For the cost effectiveness analysis, the primary outcome was the number of pain disability-free days (PDFDs) that patients experienced during the 12-month study period. We had considered also analyzing EQ-5D quality of life scores but there were no differences between TAU and intervention patients, perhaps because the EQ-5D may not be sensitive enough to detect small to moderate changes. ${ }^{30,31}$ The number of PDFDs was computed from 3, 6, and 12 month RMDQ scores following methods similar to those employed by Lave et al ${ }^{32}$ to compute depression-free days. ${ }^{33,34}$ RMDQ scores at the beginning and end of each time interval were used to estimate pain disability for each day in that interval; we regarded patients with scores of 5 or lower as fully pain disability free and those with scores of 19 or higher as fully pain disabled. ${ }^{35,36}$ For patients with RMDQ scores from 6 to 18 , the proportion of days spent in pain disability was assumed to increase linearly with the score. The total number of PDFDs over the study period was obtained by summing PDFDs across time intervals.

\section{Costs}

Data on VA treatment costs incurred by intervention and TAU group patients were obtained directly from the VA's Decision Support System (DSS) for all utilization except certain APT team activities that were not recorded in this system. DSS contains comprehensive information on fixed, variable, and indirect costs incurred by the VA on all inpatient, outpatient, surgical, and pharmaceutical utilization, but does not include all costs related to outside healthcare 
providers or financing of capital expenses. ${ }^{37}$ DSS employs a microcosting approach whereby treatment costs are computed by cumulating the costs of individual components of the treatment. ${ }^{38,39}$ The DSS system has been used for other VA cost analyses. ${ }^{34,40}$

The intervention team used a Microsoft Access database to keep track of activities not recorded in DSS; this included time spent on telephone and in-person contacts with participants which they estimated on a daily or weekly basis depending on the frequency of the activity. DSS costs for comparable activities were used to approximate costs of APT team patient care activities that were not recorded in the DSS system. Contact duration (time), contact type (in-person or telephone), and clinician profession were used to identify comparable activities. Including all fixed and indirect costs, in-person consultations with the team care manager, internist, and physical therapist were assigned hourly costs of $\$ 271.30$, $\$ 313.60$, and \$145.78, respectively. DSS costs for telephone consultations unrelated to the APT intervention by the team internist were, on average, $90 \%$ of the costs of in-person encounters of similar duration. Based on this observation, team internist and care manager telephone encounters with intervention group patients were assigned $90 \%$ of the costs of in-person encounters of similar duration. Additional patient care-related activities (eg, weekly case conferences and group educational meetings) by the team care manager and internist that exceeded the indirect care-related work associated with normal clinical practice were assigned costs based on inperson patient encounter rates. For intervention team, patient care activities that could not be ascribed to individual patients, costs were assigned to patients in proportion to the amount of time that the intervention team spent on care directly attributable to those patients.

Costs of training time for the team care manager, internist, and physical therapist were calculated using their hourly salary plus benefits rates. Primary care clinicians' training time costs were calculated using the hourly salary plus benefits rate of the team internist for all physicians and the main VAMC site's average nurse practitioner hourly salary plus benefits rate was used for all nurse practitioners. Other costs, divided equally among intervention group patients, included a video/DVD provided to intervention group patients $(\$ 327.50)$ and travel expenses related to APT team training $(\$ 2,321.84)$.

A regression model of the natural logarithm of total VA costs was used to analyze adjusted differences in costs between TAU and intervention group patients; such semi-log models are commonly used for skewed cost data. ${ }^{41} \mathrm{We}$ also compute the incremental effect of the intervention and other key predictors of costs in this nonlinear regression, for selected patient profiles. ${ }^{42}$

\section{RESULTS}

\section{Unadjusted Patient Characteristics, Outcomes, and Costs}

Table 1 summarizes baseline characteristics, quality of life, and pain outcomes, PDFDs, as well as VA treatment costs for intervention and TAU group patients. There were no
TABLE 1. Patient Characteristics, Outcomes, and Costs*

\begin{tabular}{|c|c|c|}
\hline Variable & $\begin{array}{c}\text { Intervention } \\
\text { Group } \\
\text { (n = 187) Mean } \\
\text { (SD) or \% }\end{array}$ & $\begin{array}{l}\text { Treatment as } \\
\text { Usual Group } \\
\text { (n = 214) Mean } \\
\text { (SD) or \% }\end{array}$ \\
\hline \multicolumn{3}{|l|}{ Demographics } \\
\hline Age & $62.1(11.3)$ & $61.3(12.3)$ \\
\hline Sex, male & 92 & 92 \\
\hline \multicolumn{3}{|l|}{ Baseline health } \\
\hline PHQ-9 score $^{\dagger}$ & $8.1(5.7)$ & $8.4(6.0)$ \\
\hline $\begin{array}{l}\text { Opioid prescription } 6 \text { mo } \\
\text { prior to enrollment }\end{array}$ & 44 & 42 \\
\hline Chronic disease score & $5.0(3.1)$ & $4.9(3.0)$ \\
\hline EQ-5D score ${ }^{\S}$ & $0.6(0.2)$ & $0.6(0.2)$ \\
\hline Roland-Morris score & $14.9(4.4)$ & $14.5(4.4)$ \\
\hline \multicolumn{3}{|l|}{ Outcomes } \\
\hline 12-mo EQ-5D score & $0.6(0.2)$ & $0.6(0.2)$ \\
\hline 12-mo Roland-Morris score & $13.3(5.7)$ & $14.2(5.6)$ \\
\hline $\begin{array}{l}\text { Pain disability-free days } \\
0-3 \text { mo }\end{array}$ & $31.3(25.3)$ & $30.0(26.6)$ \\
\hline $\begin{array}{l}\text { Pain disability-free days } \\
3-6 \text { mo }\end{array}$ & $34.4(28.5)$ & $30.2(28.3)$ \\
\hline $\begin{array}{l}\text { Pain disability-free days } \\
\text { 6-12 mo }\end{array}$ & $74.1(59.1)$ & $63.0(57.7)$ \\
\hline $\begin{array}{l}\text { Pain disability-free days } \\
0-12 \text { mo }\end{array}$ & $141.8(108.3)$ & $124.1(107.5)$ \\
\hline \multicolumn{3}{|l|}{ Costs } \\
\hline $\begin{array}{l}\text { VA treatment costs in year } \\
\text { prior to enrollment, } \$\end{array}$ & $6079(7068)$ & $7445(10,899)$ \\
\hline $\begin{array}{l}\text { VA treatment costs while } \\
\text { enrolled in study excluding } \\
\text { intervention team activities, } \$\end{array}$ & $10,071(14,504)$ & $8920(13,131)$ \\
\hline $\begin{array}{l}\text { Costs of intervention team } \\
\text { activities, } \$\end{array}$ & $1192(405)$ & - \\
\hline Total VA costs, $\$$ & $11,263(14,566)$ & $8920(13,131)$ \\
\hline
\end{tabular}

*None of the univariate differences between the intervention and treatment as usual groups were statistically significant at the $P<0.05$ level.

'Patient Health Questionnaire-9 score, range 0 to 27.

${ }^{\ddagger}$ Chronic disease score is the RxRisk- $\mathrm{V}$ score which uses prescription data to determine medical comorbidities, range 0 to 45 .

${ }^{\S} \mathrm{EQ}-5 \mathrm{D}$ score, range -0.109 to 1 .

"Roland-Morris Disability Questionnaire score, range 0 to 24 .

"Computed from Roland-Morris Disability Questionnaire scores.

statistically significant differences between the 2 groups on baseline health and demographic characteristics. Mean VA treatment costs in the 12 months prior to study enrollment were $\$ 6079$ and $\$ 7445$ for intervention and TAU patients, respectively. Based on RMDQ scores at 3, 6, and 12 month intervals, intervention and TAU group patients were computed to have been pain disability free on average for 142 and 124 days, respectively, during the 12-month study period. APT team activities added $\$ 1192$ in costs for intervention patients so that total VA costs were $\$ 11,263$ for intervention group patients and $\$ 8920$ for TAU group patients. Figure 1 shows the distribution of log total costs for TAU and intervention group patients.

\section{Adjusted PDFDs}

Table 2 shows regression models for PDFDs that patients experienced during the study period as well as for the 


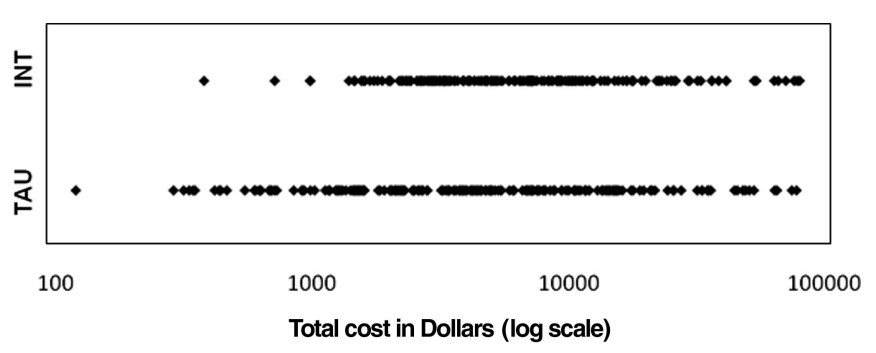

FIGURE 1. Distribution of costs for TAU and intervention group patients.

natural logarithm of total VA costs. Independent variables included in both regression models were intervention status, sex, age, depression severity, opioid prescription in the 6 months prior to enrollment, and baseline chronic disease burden (RxRisk-V score ${ }^{44}$ ). In addition, baseline RMDQ score was included in the PDFDs model, while VA treatment costs in the year prior to enrollment were included in the costs model. An alternative analysis that included baseline RMDQ and prior-year VA treatment costs in both models yielded results very similar to those presented below.

Baseline pain disability accounted for most of the explanatory power of the pain disability model $\left(\delta R^{2}>0.38\right)$ - each unit increase in pain as measured by the baseline RMDQ score predicted 18.7 fewer PDFDs $(P<0.001)$. A unit increase in disease burden as measured by the chronic disease score (RxRisk-V score) predicted 3.2 fewer PDFDs $(P=0.016)$. Patients in the intervention group experienced an average of
16.6 more PDFDs than those in the TAU group over the study year $(P=0.016)$.

\section{Adjusted Costs}

Patients in the APT intervention group incurred $71.5 \%$ higher adjusted costs than those in the TAU group $(P<$ 0.001). Among SEACAP patients, each one-year increase in age was associated with a $0.9 \%$ increase in costs $(P=0.03)$. A one-unit increase in severity of depression measured by the Patient Health Questionnaire-9 score (PHQ-9) was associated with a $2.1 \%$ increase $(P=0.012)$, while a one-unit increase in the baseline chronic disease burden (RxRisk-V score) resulted in a $7.9 \%$ increase $(P<0.001)$ in costs. A $1 \%$ increase in VA treatment costs in the year prior to study enrollment was associated with a $0.45 \%$ increase $(P<0.001)$ in costs incurred during the study period.

\section{Adjusted Incremental Effects of the Intervention and Patient Characteristics on Costs}

Table 3 presents the predicted 12-month mean TAU and intervention group VA costs for patients with 3 different profiles. To further illustrate the variation in these costs, Table 3 provides estimates of the incremental dollar effects of selected changes in patient baseline characteristics, and shows how changes in patient attributes can alter the cost of a PDFD produced by the intervention. The sizes of changes in baseline continuous variables were chosen to approximate 1 standard deviation. A smearing estimator was used in all retransformations ${ }^{45}$; an analysis of error terms from the cost regression found no evidence of heteroscedasticity.

\begin{tabular}{|c|c|c|c|c|}
\hline \multirow[b]{2}{*}{ Variable } & \multicolumn{2}{|c|}{$\begin{array}{l}\text { Pain Disability-Free Days } \\
\quad\left(\mathrm{n}=346 ; R^{2}=0.66\right)\end{array}$} & \multicolumn{2}{|c|}{$\begin{array}{c}\text { Log Total Costs* } \\
\left(\mathrm{n}=398 ; R^{2}=0.46\right)\end{array}$} \\
\hline & $\begin{array}{c}\text { Regression Coefficient } \\
(95 \% \text { CI })\end{array}$ & $P$ & $\begin{array}{c}\text { Regression Coefficient } \\
(95 \% \text { CI })\end{array}$ & $P$ \\
\hline Intercept & $409.9(364.5,455.4)$ & $<0.001$ & $3.4(2.6,4.3)$ & $<0.001$ \\
\hline $\begin{array}{l}\text { Intervention (reference category- } \\
\text { treatment as usual group) }\end{array}$ & $16.6(3.1,30.1)$ & 0.016 & $0.5(0.4,0.7)$ & $<0.001$ \\
\hline \multicolumn{5}{|l|}{ Demographics } \\
\hline Female & $-12.3(-38.5,13.8)$ & 0.355 & $0.2(-0.1,0.6)$ & 0.147 \\
\hline Age & $0.2(-0.4,0.8)$ & 0.558 & $0.0(0.0,0.0)$ & 0.03 \\
\hline \multicolumn{5}{|l|}{ Baseline health } \\
\hline PHQ-9 score ${ }^{\dagger}$ & $-0.5(-1.9,0.9)$ & 0.468 & $0.0(0.0,0.0)$ & 0.012 \\
\hline $\begin{array}{l}\text { Opioid prescribed } 6 \text { mo prior } \\
\text { to enrollment }\end{array}$ & $-7.7(-23.4,8.0)$ & 0.337 & $0.0(-0.2,0.3)$ & 0.662 \\
\hline Chronic disease score ${ }^{\ddagger}$ & $-3.2(-5.8,-0.6)$ & 0.016 & $0.1(0.0,0.1)$ & $<0.001$ \\
\hline RMDQ score ${ }^{\S}$ & $-18.7(-20.6,-16.9)$ & $<0.001$ & - & - \\
\hline \multicolumn{5}{|l|}{ Costs } \\
\hline $\begin{array}{l}\text { VA treatment costs in year } \\
\text { prior to enrollment }\end{array}$ & - & - & $0.4(0.4,0.5)$ & $<0.001$ \\
\hline \multicolumn{5}{|c|}{$\begin{array}{l}\text { *The estimate of the percentage impact of an independent variable on costs is related to the variable's regression coefficient }(B) \\
\text { as follows: } 100 \times B \text { for a unit change in a continuous predictor, and } 100 \times(\exp (B)-1) \text { for a dichotomous predictor }(43) \text {. When } \\
\text { the predictor variable is also expressed as a natural logarithm (costs in } 12 \text { months preceding study enrollment in the model in Table } \\
\text { 2), then the variable's regression coefficient is interpreted as the predicted percentage change for a } 1 \% \text { change in the value of the } \\
\text { predictor. } \\
\text { †Patient Health Questionnaire- } 9 \text { score, range } 0 \text { to } 27 \text {. } \\
\text { †Chronic disease score is the RxRisk-V score which uses prescription data to determine medical comorbidities, range } 0 \text { to } 45 \text {. } \\
\text { \$Roland-Morris Disability Questionnaire score, range } 0 \text { to } 24 \text {. }\end{array}$} \\
\hline
\end{tabular}


TABLE 3. Predicted Mean Costs and Incremental Effects of Predictors

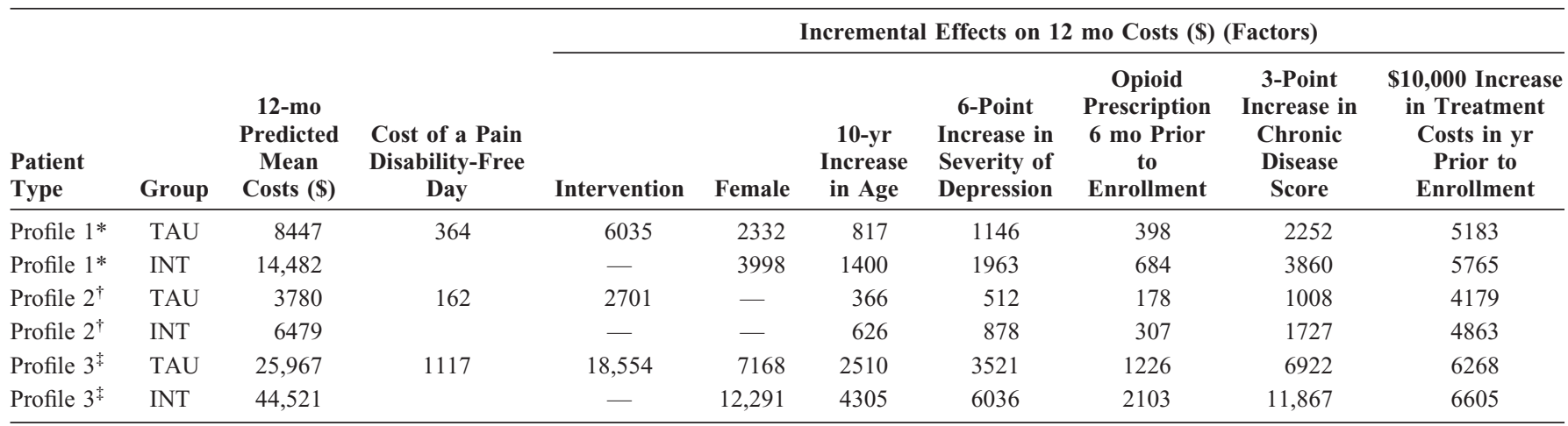

*Profile 1: 62-yr-old male veteran with depression severity of 8 on PHQ-9 scale, no opioid prescription in the 6 mo prior to enrollment, with a chronic disease score of 5 and treatment costs of $\$ 7444$ in the year preceding enrollment in the study.

†Profile 2: 35-yr-old female veteran with depression severity of 2 on PHQ-9 scale, no opioid prescription in the 6 mo prior to enrollment, chronic disease score of 2, and \$2000 in treatment costs in the year prior to study enrollment.

*Profile 3: 75-yr-old male veteran with depression severity of 16 on PHQ-9 scale, an opioid prescription in the 6 mo prior to enrollment, chronic disease score of 8 , and $\$ 25,000$ in treatment costs in the year prior to study enrollment

TAU refers to treatment as usual group.

INT refers to APT intervention group.

Profile 1 depicts a patient with baseline characteristics close to the mean for those enrolled in SEACAP. Profiles 2 and 3 depict patients with characteristics typically associated with lower and higher costs, respectively. For the patient in Profile 1, the APT intervention predicts a $\$ 6035$ increase in costs; the cost per PDFD produced by the APT intervention is $\$ 364$. Profile 2 reflects a younger, female veteran with a relatively low burden of chronic disease and depression, and relatively low costs in the year preceding enrollment in SEACAP. For such a patient, the predicted increase in costs due to the APT intervention is $\$ 2701$, and $\$ 162$ is the predicted cost of a PDFD produced by the intervention. Profile 3 represents an older male veteran with high burdens of chronic disease and depression, as well as high costs in the year prior to enrollment. The predicted increase in costs due to APT is $\$ 18,554$ for such a patient, and the predicted cost per PDFD produced is $\$ 1117$.

\section{DISCUSSION}

We previously found that a collaborative approach to treating chronic pain in a primary care setting was moderately effective in decreasing pain-related disability, pain interference, pain intensity, and depression severity scores compared with usual care over a 12-month period. We report here that the intervention resulted in more PDFDs compared with usual care. The intervention group had significantly higher costs than the usual care group, likely attributable to the cost of the intervention as well as changes in treatment as a result of the intervention.

With an increased average cost of about $\$ 2300$ per patient for the intervention over TAU during the study year, our findings fall on the low end of costs for commonly-used chronic pain interventions. The average number of direct patient contacts (in-person or telephone) with the APT intervention team was approximately 11 , which corresponds to \$209 per contact. In comparison, the costs of visits to phys- ical therapists and chiropractors were \$221 and \$185 in 1995 dollars, respectively, per month in a randomized back pain study, ${ }^{46}$ which translates to about $\$ 2600$ and $\$ 2200$ per year. Management of pain with medication often exceeds $\$ 4000$ per year while the minimum cost of lumbar surgery is estimated at $\$ 15,000 .^{3}$

Previous studies of other collaborative care interventions, in particular for depression and panic disorder, have shown much lower intervention costs than we found. ${ }^{47-49}$ APT participants experienced an average of 16 more PDFDs over 12 months than those in usual care, resulting in a cost of \$364 per PDFD for a typical participant. Yet, in a collaborative care intervention aimed at reducing depression among older adults, intervention patients had 107 more depressionfree days over 24 months than usual care patients, corresponding to an incremental outpatient cost per depressionfree day of $\$ 2.76 .{ }^{47}$ In another study aimed at increasing anxiety-free days among people with panic disorder, a collaborative approach helped people in the intervention group have about 75 more anxiety-free days over 12 months at a cost savings of $\$ 4$ per anxiety-free day. ${ }^{48}$ Our use of micro cost data to identify comparable activities for patient carerelated work by the intervention team contributed to our high estimates of intervention costs. Prior studies have used provider salary and benefits plus a markup (typically 30\%) for overhead (eg, Katon et $\mathrm{al}^{47}$ ), which would produce lower cost estimates. While salary, benefits, and overhead may provide an accurate measure of incremental costs in clinical trial settings, using microcosts for comparable activities provides a better estimate of costs if interventions were incorporated into standard care.

In addition, while our primary outcome measure of PDFDs was modeled on Lave et al's ${ }^{32}$ method of calculating depression-free days, psychometric differences in the measures used for depression (Hamilton Depression Rating Scale) and pain (RMDQ), as well as differences in the 
disorders themselves, may contribute to differences in the numbers of disorder-free days calculated. Overall, these methodological differences in calculation of costs and disorder-free days limit our ability to compare the cost-effectiveness of APT to previous collaborative interventions.

Given the relatively high cost per PDFD, it would be helpful to identify subgroups for which APT is more costeffective. For example, preliminary SEACAP analyses show a relationship between baseline RMDQ score and likelihood of 12 month response (defined as a $30 \%$ reduction in RMDQ): for every unit increase in baseline RMDQ score, the odds of response decrease by $9 \%(P=0.002)$. Additional responder analyses are in progress. In addition, in Table 3 , we presented statistical estimates of costs for 3 types of patients, which show that younger, female veterans with a low chronic disease burden have predicted costs of $\$ 162$ per PDFD. Taken together, these findings suggest that APT may be more cost effective for younger and overall healthier veterans who have lower baseline pain-related disability. For veterans with greater baseline pain-related disability or more chronic conditions, other types of pain care (eg, referral based approaches) might be more cost effective.

Another potential approach to improving the cost-effectiveness of APT would be through economies of scale, by treating more patients using the same resources. However, because much of the intervention focused on individualized care (goal-setting, treatment regimen review), we would not expect to see much economy of scale if implemented in a larger population. Furthermore, one-time costs such as clinician and intervention team training were small contributors to the overall cost of the intervention. In an analysis taking out all intervention team costs, intervention group patients continued to have $26 \%$ higher adjusted costs than the TAU group. We are currently conducting a 30-month assessment to see if intervention treatment effects persist. If so, the intervention may become cost-effective over time.

This study has several limitations. The treatment setting of the VA system differs in many respects, including patient demographics, from other US healthcare systems. Our study sample was comprised largely of older white men and results may not generalize to other populations. We had to estimate the costs of the intervention, which were not captured in the VA costing system; our use of costs of comparable services may have led to overestimates relative to many other studies that have relied on provider salary and benefits information. For example, we assigned costs to most intervention team activities at the same rates used for direct patient encounters. Finally, our study looked at incremental costs from a VA health system perspective, which does not take into account effects of the intervention on healthcare received elsewhere. We do note that intervention and TAU patients reported similar numbers of contacts with outside providers.

The APT collaborative care intervention of the SEACAP study resulted in more PDFDs and higher costs than usual care over the 12-month follow-up period. The wide range in cost to obtain an additional PDFD suggests that the intervention may be quite costly for older people with many comorbidities and long-standing pain, perhaps suggest- ing that the intervention in its current form be targeted to certain groups of patients. We are currently conducting a 30-month follow-up to ascertain whether the benefits experienced by the intervention group are maintaining or changing over time, which may affect the cost-benefit ratio.

\section{REFERENCES}

1. Verhaak PF, Kerssens JJ, Dekker J, et al. Prevalence of chronic benign pain disorder among adults: a review of the literature. Pain. 1998;77: 231-239.

2. Gureje O, Von Korff M, Simon GE, et al. Persistent pain and well-being: a World Health Organization Study in Primary Care. JAMA. 1998;280: $147-151$

3. Turk DC. Clinical effectiveness and cost-effectiveness of treatments for patients with chronic pain. Clin J Pain. 2002;18:355-365.

4. Bair MJ, Robinson RL, Katon W, et al. Depression and pain comorbidity: a literature review. Arch Intern Med. 2003;163:2433-2445.

5. Stewart WF, Ricci JA, Chee E, et al. Lost productive time and cost due to common pain conditions in the US workforce. JAMA. 2003;290: 2443-2454.

6. Grimshaw JM, Shirran L, Thomas R, et al. Changing provider behavior: an overview of systematic reviews of interventions. Med Care. 2001; 39:II2-II45.

7. Bodenheimer T, Wagner EH, Grumbach K. Improving primary care for patients with chronic illness: the chronic care model, Part 2. JAMA. 2002;288:1909-1914

8. Williams JW Jr, Gerrity M, Holsinger T, et al. Systematic review of multifaceted interventions to improve depression care. Gen Hosp Psychiatry. 2007;29:91-116.

9. Bodenheimer T, Wagner EH, Grumbach K. Improving primary care for patients with chronic illness. JAMA. 2002;288:1775-1779.

10. Dobscha SK, Corson K, Leibowitz RQ, et al. Rationale, design, and baseline findings from a randomized trial of collaborative care for chronic musculoskeletal pain in primary care. Pain Med. 2008;9:10501064.

11. Dobscha SK, Corson K, Perrin NA, et al. Collaborative care for chronic pain in primary care: a randomized trial. JAMA. 2009;301:1242-1252.

12. Roland M, Morris R. A study of the natural history of back pain. Part I: development of a reliable and sensitive measure of disability in low-back pain. Spine. 1983;8:141-144.

13. Roland M, Fairbank J. The Roland-Morris Disability Questionnaire and the Oswestry Disability Questionnaire. Spine. 2000;25:3115-3124.

14. Von Korff M, Ormel J, Keefe FJ, et al. Grading the severity of chronic pain. Pain. 1992;50:133-149.

15. Kroenke K, Spitzer RL, Williams JB. A new measure of depression severity: the PHQ-9. J Gen Intern Med. 2000;15:78.

16. Wells KB, Sherbourne C, Schoenbaum M, et al. Impact of disseminating quality improvement programs for depression in managed primary care: a randomized controlled trial. JAMA. 2000;283:212-220.

17. Katon W, Von Korff M, Lin E, et al. Stepped collaborative care for primary care patients with persistent symptoms of depression: a randomized trial. Arch Gen Psychiatry. 1999;56:1109-1115.

18. Katon W, Von Korff M, Lin E, et al. Collaborative management to achieve treatment guidelines: impact on depression in primary care. JAMA. 1995;273:1026-1031

19. Weingarten SR, Henning JM, Badamgarav E, et al. Interventions used in disease management programmes for patients with chronic illness-which ones work? Meta-analysis of published reports. BMJ. 2002;325:925.

20. DeBattista C, Trivedi MH, Kern JK, et al. The status of evidence-based guidelines and algorithms in the treatment of depression. Psychiatr Ann. 2002;32:658-663.

21. Kerns RD, Haythornthwaite JA. Depression among chronic pain patients: cognitive-behavioral analysis and effect on rehabilitation outcome. J Consult Clin Psychol. 1988;56:870-876.

22. Becker N, Sjogren P, Bech P, et al. Treatment outcome of chronic non-malignant pain patients managed in a Danish multidisciplinary pain centre compared to general practice: a randomized controlled trial. Pain. 2000;84:203-211

23. Knab JH, Wallace MS, Wagner RL, et al. The use of a computer-based 
decision support system facilitates primary care physicians' management of chronic pain. Anesth Analg. 2001;93:712-720.

24. Jensen MP, Turner JA, Romano JM. Correlates of improvement in multidisciplinary treatment of chronic pain. J Consult Clin Psychol. 1994;62:172-179.

25. VA-DoD. Management of opioid therapy for chronic pain. Washington, DC: VA/DoD Clinical Practice Guideline Workshop Group, Veterans Health Administration, Department of Veterans Affairs and Health Affairs, Department of Defense (DoD). Office of Quality and Performance publication 10Q-CPG/OT-03;2003. Available at: http://vaww.oqp.med. va.gov/CPGintra/cpg/cot/ot_basehtm. Accessed June 21, 2007.

26. American Geriatric Society. The management of chronic pain in older persons: AGS panel on chronic pain in older persons. J Am Geriatr Soc. 1998;46:635-651.

27. Ferrell B, Casarett D, Epplin J, et al. The management of persistent pain in older persons. J Am Geriatr Soc. 2002;50:S205-S224.

28. Von Korff M, Balderson BH, Saunders K, et al. A trial of an activating intervention for chronic back pain in primary care and physical therapy sessions. Pain. 2005;113:323-330.

29. Grotle M, Brox JI, Vollestad NK. Functional status and disability questionnaires: what do they assess? A systematic review of backspecific outcome questionnaires. Spine. 2005;30:130-140.

30. Harper R, Brazier JE, Waterhouse JC, et al. Comparison of outcome measures for patients with chronic obstructive pulmonary disease (COPD) in an outpatient setting. Thorax. 1997;52:879-887.

31. Jenkinson C, Gray A, Doll H, et al. Evaluation of index and profile measures of health status in a randomized controlled trial. Comparison of the Medical Outcomes Study 36-Item Short Form Health Survey, EuroQol, and disease specific measures. Med Care. 1997;35:11091118.

32. Lave JR, Frank RG, Schulberg HC, et al. Cost-effectiveness of treatments for major depression in primary care practice. Arch Gen Psychiatry. 1998;55:645-651.

33. Simon GE, Katon WJ, VonKorff M, et al. Cost-effectiveness of a collaborative care program for primary care patients with persistent depression. Am J Psychiatry. 2001;158:1638-1644.

34. Liu CF, Hedrick SC, Chaney EF, et al. Cost-effectiveness of collaborative care for depression in a primary care veteran population. Psychiatr Serv. 2003;54:698-704.

35. Trout A, Kallmes D, Gray L, et al. Evaluation of vertebroplasty with a validated outcome measure: the Roland-Morris Disability Questionnaire. Am J Neuroradiol. 2005;26:2652-2657.

36. Patrick DL, Deyo RA, Atlas SJ, et al. Assessing health-related quality of life in patients with sciatica. Spine. 1995;20:1899-1908; discussion 1909.

37. Barnett PG, Rodgers JH. Use of the decision support system for VA cost-effectiveness research. Med Care. 1999;37:AS63-AS70.

38. VA Information Resource Center. VIReC Research User Guide: VHA DSS Clinical National Data Extracts FY2000-FY2004. Hines, IL: Edward J Hines Jr VA Hospital; 2005.

39. Barnett PG. An improved set of standards for finding cost for costeffectiveness analysis. Med Care. 2009;47(suppl 1).

40. Wagner TH, Richardson SS, Vogel B, et al. Cost of inpatient rehabilitation care in the Department of Veterans Affairs. $J$ Rehabil Res Dev. 2006;43:929-938.

41. Diehr P, Yanez D, Ash A, et al. Methods for analyzing health care utilization and costs. Annu Rev Public Health. 1999;20:125-144.

42. Sharma R, Haas M, Stano M. Patient attitudes, insurance, and other determinants of self-referral to medical and chiropractic physicians. Am J Public Health. 2003;93:2111-2117.

43. Halvorsen R, Palmquist R. The interpretation of dummy variables in semilogarithmic equations. Am Econ Rev. 1980;70.

44. Sloan KL, Sales AE, Liu CF, et al. Construction and characteristics of the RxRisk-V: a VA-adapted pharmacy-based case-mix instrument. Med Care. 2003;41:761-774.

45. Duan N. Smearing estimate: a nonparametric retransformation method. J Am Stat Assoc. 1983;78:605-610.

46. Cherkin DC, Deyo RA, Battie M, et al. A comparison of physical therapy, chiropractic manipulation, and provision of an educational booklet for the treatment of patients with low back pain. $N$ Engl J Med. 1998;339:1021-1029.

47. Katon WJ, Schoenbaum M, Fan MY, et al. Cost-effectiveness of improving primary care treatment of late-life depression. Arch Gen Psychiatry. 2005;62:1313-1320.

48. Katon WJ, Roy-Byrne P, Russo J, et al. Cost-effectiveness and cost offset of a collaborative care intervention for primary care patients with panic disorder. Arch Gen Psychiatry. 2002;59:1098-1104.

49. Von Korff M, Katon W, Bush T, et al. Treatment costs, cost offset, and cost-effectiveness of collaborative management of depression. Psychosom Med. 1998;60:143-149. 